\title{
TERCEIROS MOLARES INCLUSOS: revisão de literatura
}

DOI: $10.22289 / 2446-922 X . V 3 N 1 A 4$

\author{
Alziro Fernando da Silveira Matos ${ }^{1}$ \\ Lucas Eduardo Vieira \\ Lilian de Barros
}

\section{RESUMO}

Dentes inclusos são definidos como dentes que não irromperam na cavidade bucal, chegada sua época fisiológica de irrupção e, estes elementos, na grande maioria dos casos, podem ficar inclusos por toda a vida do paciente. O objetivo deste trabalho é elucidar sobre a real necessidade de se extrair os terceiros molares impactados, ou seja, relatar as principais indicações e contraindicações para a exodontia dos mesmos, destacando a extrema importância na obtenção do conhecimento pelo cirurgião dentista quanto: técnicas cirúrgicas, custo-benefício de cada procedimento, interpretação radiográfica, complicações pós-operatórias, classificações de inclusões dentárias e, avaliação crítica quando for realizar o procedimento cirúrgico. Utilizou-se uma pesquisa bibliográfica com abordagem qualitativa descritiva. Foram consultadas 17 referências publicadas entre 2004 e 2016. Observou-se que de fato há uma enorme discordância na literatura em geral sobre a indicação e contraindicação da extração de terceiros molares impactados.

Palavras-chave: Terceiros molares, Dentes inclusos e Cirurgia bucal.

\section{ABSTRACT}

Inclusive teeth are defined as teeth that did not erupt in the oral cavity, their physiological time of irruption has arrived, and these elements, in the great majority of cases, can be included throughout the patient's life. The objective of this study is to elucidate the real need to extract impacted third molars, that is, to report the main indications and contraindications for their extraction, highlighting the extreme importance in obtaining the knowledge by the dental surgeon regarding: surgical techniques, cost - benefit of each procedure, radiographic interpretation, postoperative complications, classification of dental inclusions, and critical evaluation, when performing the surgical procedure. We used a bibliographical research with a descriptive qualitative approach. A total of 17 references published between 2004 and 2016 were consulted. It was observed that there is a great deal of disagreement in the literature on the indication and contraindication of the extraction of impacted third molars.

Keywords: Third molars, Teeth included and Oral surgery.

\section{INTRODUÇÃO}

\footnotetext{
${ }^{1}$ Endereço eletrônico de contato: fernandomatosjp@hotmail.com.
}

Recebido em 02/06/2017. Aprovado pelo Conselho Editorial e aceito para publicação em 09/06/2017.

Rev. Psicol Saúde e Debate. Jan., 2017:3(1):34-49. 
$\mathrm{Na}$ Odontologia atual, existe uma grande discordância sobre a terminologia correta da definição de dente incluso. O mesmo pode ser classificado como aquele dente, que chegada sua época de erupção, ou na véspera, não a realizou. Também podemos classificar como dente que permaneceu ou ainda permanece sobre tecido duro ou mole, podendo estar impactado sob tecido duro (intraóssea), ou tecido mole (subgengival); onde sua visualização será possível somente por meios radiográficos. $(1,2,3,4)$

Podem, também, ser classificados como semi-inclusos, quando apresentarem apenas parte de sua coroa no meio bucal. ${ }^{(1,3)}$

Se tratando da frequência de impactação, os terceiros molares são os que aparecem com mais frequência $(90 \%)$, seguidos pelos caninos superiores $(5 \%)$, prémolares inferiores e supranumerários (5\%). ${ }^{(5)}$

O elemento dentário que estiver em processo de erupção, ou seja, quando não está na cronologia correta de irrupção fisiológica, é denominado não erupcionado. ${ }^{(6)}$

É muito importante a decisão de se indicar ou não a exodontia de terceiros molares. Para o auxílio nesta decisão, pode-se utilizar alguns artifícios: anamnese completa do paciente e exame clínico criterioso; sempre complementando com radiografia panorâmica atual do paciente. ${ }^{(2)}$

As radiografias panorâmicas possuem a função de auxílio e previsibilidade das cirurgias. Sendo assim, auxiliam no correto planejamento cirúrgico de cada caso, permitindo estabelecer uma conduta cirúrgica adequada. ${ }^{(1,2,3,4,7)}$

As classificações mais utilizadas para dentes inclusos são as de Winter e Pell \& Gregory. São classificações muito populares devido a sua simplicidade facilitando, assim, a comunicação entre profissionais; sendo vantajoso em relatos de casos clínicos, grau de complexidade dos casos e prognóstico $(4,8)$.

Winter, em 1926, criou uma classificação dos terceiros molares, avaliando a relação do longo eixo do terceiro molar em relação ao longo eixo do segundo molar. $(2,3,4,8)$.

Rev. Psicol Saúde e Debate. Jan., 2017:3(1):34-49. 
Pell \& Gregory desenvolveram, em 1933, duas maneiras eficazes de classificar os terceiros molares, sendo uma relacionada à profundidade de inclusão e outra, à inclusão dentro do ramo mandibular. $(2,3,8)$

Com a evolução humana, o sistema estomatognático e vários outros sofreram grandes modificações no decorrer dos tempos, evoluindo concomitantemente com a alimentação do homem. ${ }^{(5,8,9)}$

Todo elemento dentário que permanece impactado é propício à desenvolver condições adversas ao paciente ou, às vezes, estes permanecem impactados por toda a vida e, nada acontece. Na literatura, existem uma ampla discussão sobre a real necessidade de extração de terceiros molares impactados. Alguns autores defendem que a relação entre elemento impactado e patologias associadas é baixa e, que não há critérios que comprovem se o mesmo irá, de fato, erupcionar. A relação entre apinhamento dentário e terceiro molar não é comprovada e a preservação do elemento pode vir a ser útil no futuro, em caso de transplante de perdas dentárias. ${ }^{(10)}$.

Em contrapartida, é importante ressaltar que associações, de lesões patológicas e terceiros molares não são comuns mas, quando existentes, aumentam a agressividade cirúrgica e a qualidade de vida pós-operatória. ${ }^{(10)}$

Deve-se sempre levar em consideração indicações e contra-indicações de remoção de terceiros molares, não esquecendo da importância da prevenção. É importante levar em consideração se realmente valerá a pena removê-los. Seguindo esta filosofia, os dentes impactados devem ser removidos antes que complicações apareçam, levando sempre em consideração o custo/benefício da cirurgia ${ }^{(6)}$

\section{MÉTODOS}

Para o desenvolvimento dessa revisão bibliográfica com abordagem qualitativa, com o intuito de discutir e colher informações sobre o tema proposto, foi realizada uma busca utilizando as seguintes palavras chave: terceiros molares, Rev. Psicol Saúde e Debate. Jan., 2017:3(1):34-49. 
dentes inclusos e cirurgia bucal, publicadas entre 2004 e 2016, na língua portuguesa. A pesquisa foi realizada nas seguintes bases de dados: Pubmed, Scielo, Bvs e Rev@odonto. Os dados encontrados foram descritos nesta revisão de literatura.

\section{REVISÃO DA LITERATURA}

\section{Fatores que levam a inclusão dentária}

A etiologia da impacção está relacionada, principalmente, à falta de espaço disponível em determinada região para o irrompimento do elemento dentário na cavidade e este chegar a exercer sua função. ${ }^{(4)}$

Outro fator importante é a falta de espaço presente (diâmetro mésio-distal) disponível. Este é comprovado pela teoria da evolução, que explica a diminuição dos maxilares como um meio de adaptação. A diminuição de estímulos mastigatórios mais intensos diminuiu a carga implantada aos maxilares, ocorrendo a diminuição dos mesmos. Mudanças importantes também ocorreram no cérebro do homo sapiens para o homo herectus. Notou-se um grande aumento volumétrico do crânio e ossos da face. ${ }^{(4,5,9)}$.

Outra teoria bastante difundida na literatura é o fator hereditário. Há relatos comprovando indivíduos da mesma família que apresentam dentes inclusos ou impactados de forma semelhante. Quando se tem um distúrbio de crescimento dos maxilares, fator que pode ser explicado tanto pela teoria evolutiva, com a mudança de alimentação (alimentos mais volumosos e difíceis de mastigar foram trocados por alimentos mais pastosos e macios), quanto pela teoria hereditária, como a inclusão de um elemento dental pela não presença de espaço na arcada. $(4,9)$.

Além da redução dos maxilares, outro acontecimento importante que ocorreu foi a diminuição da quantidade de dentes. Os quartos molares são vistos, atualmente, como dentes supranumerários. Os terceiros molares estão cada vez mais impactados e, as anodontias dos mesmos, são cada vez mais comuns. ${ }^{(5)}$

Além de causas filogenéticas, também é importante classificar inclusões dentárias por fatores sistêmicos e locais. ${ }^{(5)}$ 
Os fatores sistêmicos mais comuns são doenças que interferem no desenvolvimento esquelético do indivíduo como: raquitismo, disfunções hormonais, sífilis congênita, tuberculose, acondroplasia, mongolismo e a disostose cleidocraniana. ${ }^{(4,5)}$

Já os fatores locais são os que dificultam o irrompimento do dente, como: falta de espaço, anomalias próprias do dente (dilaceração radicular, macrodontia, quantidade de raízes), degenerações teciduais, má posição dos dentes adjacentes, perda precoce de dentes decíduos, traumas na infância durante o desenvolvimento do germe dentário, entre outros fatores. ${ }^{(5,9)}$

\section{Exame radiográfico}

Quando se trata de diagnóstico de terceiros molares inclusos, ou até de dentes supranumerários, as radiografias odontológicas são elementos essenciais. $(1,11,12)$

A radiografia Panorâmica é muito utilizada pelo fato de possuir inúmeras vantagens como: possibilidade de visualização de todo 0 complexo maxilomandibular, localização do terceiro molar em relação aos dentes vizinhos, quantidade de osso ao seu redor, a proximidade de dentes às estruturas nobres como o canal mandibular; sendo que esta proximidade deve ser bem avaliada para levantar o melhor plano de tratamento em cada caso e, a facilidade de tomada radiográfica. ${ }^{(11,12)}$

A radiografia Panorâmica é mais aceita por pacientes (principalmente crianças) pelo fato de ser realizada fora da cavidade bucal. No entanto, quando as radiografias panorâmicas não revelam informações importantes do elemento dentário em relação às estruturas nobres, torna-se necessário a utilização de outras técnicas radiográficas como: técnica de Miller-Winter, de Donovan, de Parma, lateral oblíqua da mandíbula e a tomografia computadorizada. ${ }^{(12)}$

Radiografias periapicais levam vantagem sobre a Panorâmica quando se trata em detalhamento da imagem radiografada, com mínimo de distorção. É de grande ajuda a obtenção dessa riqueza de detalhes anatômicos (posição do terceiro molar impactado em relação às estruturas nobres, número de raízes, espaço do ligamento periodontal) para facilitar o plano de tratamento de cada caso. $(1,12)$ 
No entanto, tanto as radiografias periapicais quanto as panorâmicas, possuem a desvantagem de não oferecer visualização radiográfica no sentido vestíbulo-lingual. (12)

Em muitos casos, não se consegue obter uma visualização completa do terceiro molar impactado e/ou de um elemento supranumerário devido a sua posição estar demasiadamente na distal, ou o ramo da mandíbula muito projetado; impossibilitando, assim, o correto posicionamento do filme periapical. Em casos como estes, pode-se utilizar técnicas de adaptação radiográfica. Para tanto, Miller e Winter (1914) propuseram uma técnica para visualização completa de terceiros molares impactados e dentes supranumerários. Esta técnica totaliza-se em duas tomadas radiográficas: a primeira, periapical (para visualização do elemento dentário em sentido mésio-distal e ocluso-apical) e a segunda, radiografia periapical (no sentido oclusal, para possibilitar a visualização do elemento dental no sentido vestíbulo-lingual). Se faz importante pelo fato da possibilidade da formação de uma imagem tridimensional do elemento dentário estudado. ${ }^{(12,13,14)}$

Margareth Donovan idealizou uma modificação da técnica de Miller-Winter, chamado de método de localização de Winter. Técnica indicada para situações onde o terceiro molar está localizado na região do ângulo e ramo mandibular, sempre quando não for possível a visualização das raízes do terceiro molar. Ela consiste em apoiar o filme radiográfico, de modo que o mesmo fique perpendicular ao ramo da mandíbula, apoiado pelo dedo indicador do paciente. $(12,14)$

A técnica de Parma também é de bastante utilidade na visualização de terceiros molares inclusos mésio-angulares, pelo fato da dificuldade de visualizar, na radiografia periapical convencional, a raiz distal de um dente mésio-angulado. Ela consiste em inclinar o filme em sentido distal, para pode atingir radiograficamente a raiz distal do terceiro molar ou dente supranumerário. A técnica de radiografia lateral oblíqua é menos utilizada pelos cirurgiões dentistas pelo fato da grande distorção apresentada no filme radiográfico. É uma adaptação da incidência lateral oblíqua, onde adapta-se um filme oclusal em vez de uma radiografia panorâmica convencional. Com esta técnica, pode-se observar todo a região lateral da mandíbula e, a posição dos molares em relação ao canal mandibular. ${ }^{(12)}$ 
Em casos mais complexos, onde a visualização dos terceiros molares e estruturas anatômicas importantes não estão favoráveis através das técnicas já citadas acima, pode-se optar pela realização da tomografia computadorizada.

Apesar de possuir um custo elevado mesmo nos dias de hoje e, devido à grande quantidade de radiação provocada, esta técnica vem se tornando mais comum a cada dia, e é sempre muito bem utilizada para diagnóstico e plano de tratamento em uma vasta gama odontológica. ${ }^{(12,14)}$

A tomografia computadorizada possui a grande vantagem de gerar imagens tridimensionais (3D), onde possibilita ótima visualização do elemento dentário, auxiliando no planejamento de cada caso e, acesso cirúrgico para remoção do terceiro molar com segurança e eficiência. Portanto, a grande utilidade da tomografia computadorizada é a possibilidade de visualização das estruturas anatômicas maxilares em alta definição. ${ }^{(14)}$

\section{Classificação das inclusões}

Sistemas de classificações de terceiros molares impactados foram desenvolvidos com o objetivo de comunicação entre profissionais e, para a previsibilidade cirúrgica de cada exodontia. ${ }^{(6)}$

A grande maioria destas classificações foram desenvolvidas e realizadas através das radiografias odontológicas. Radiografias Panorâmicas são as mais indicadas e utilizadas neste contexto. Ainda é de extrema importância a auto avaliação do cirurgião dentista em termos de conhecimento e habilidade. (6)

Atualmente, três sistemas de classificação de terceiros molares inclusos inferiores são mais utilizados. As três classificações classificam terceiros molares de acordo com: angulação, o plano oclusal e o ramo ascendente da mandíbula. $(2,4,5,15)$

A classificação de Winter, relaciona a posição do longo eixo do terceiro molar não irrompido em relação ao segundo molar (válida para classificar tanto terceiros molares superiores, quanto inferiores). $(2,4,5,6)$

A angulação vertical (figura: 1) é definida quando o longo eixo do terceiro molar está localizado no mesmo plano do segundo molar, ou seja, em um plano 
paralelo. Esta impactação é a segunda mais frequente, sendo a terceira mais difícil e, somam $38 \%$ de todas as impactações. ${ }^{(2,4,5,6)}$

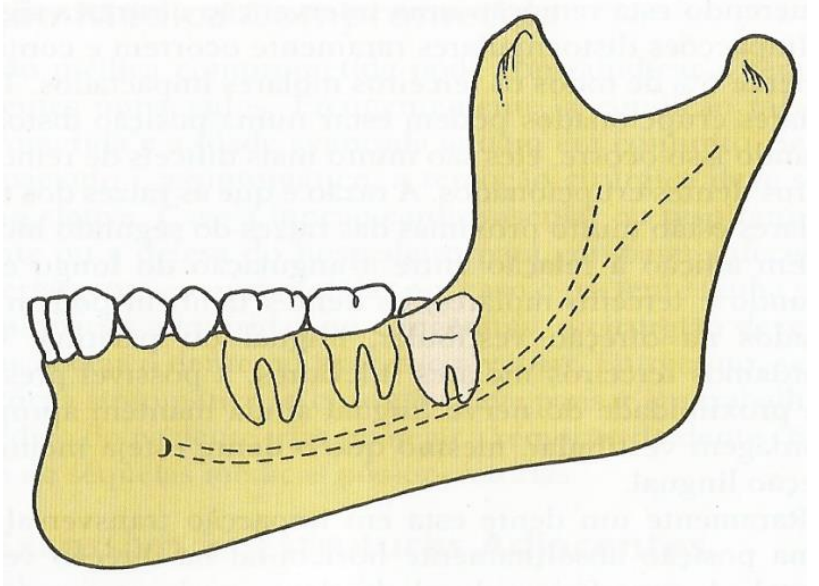

Fig.1: Apresenta impactação vertical.

Um elemento dental se encontra na posição mesioangular (figura: 2) quando a coroa do terceiro molar estiver direcionada para a mesial. Este é o tipo mais frequente correspondendo a $43 \%$ das impactações e, possui mínima dificuldade de remoção. $(2,4,5,6)$

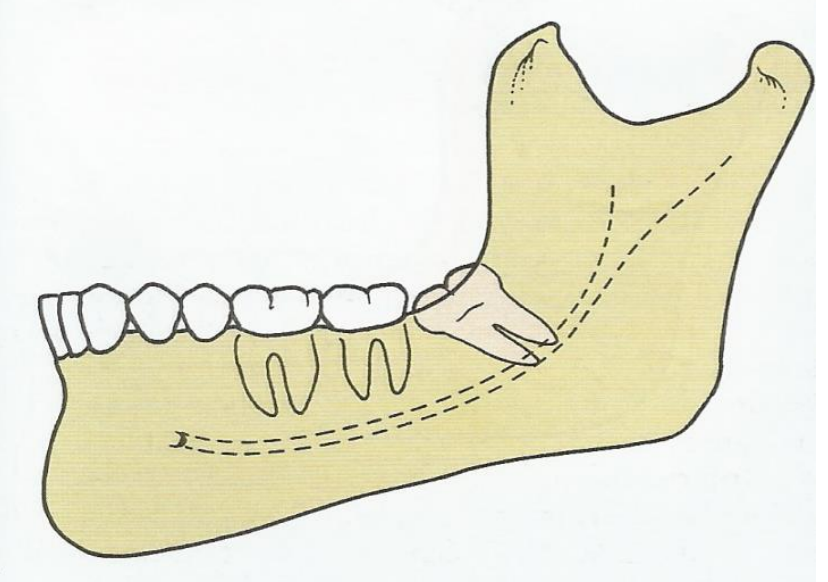

Fig. 2: Apresenta impactação mesioangular

A posição distoangular (figura: 3) é classificada quando a coroa do terceiro molar estiver localizada na posição contrária à posição mesioangular. Este tipo de impactação é considerada como rara, sendo encontrada em apenas $6 \%$ da população e, é a impactação mais complexa de remover; pelo fato da trajetória de remoção do elemento dentário ser para dentro do ramo mandibular. $(2,4,5,6)$ 


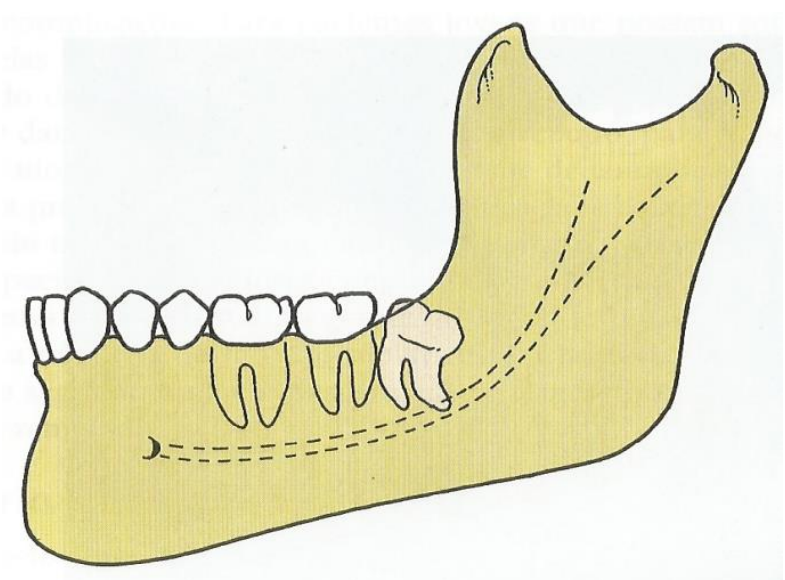

Fig. 3: Apresenta angulação distoangular

O elemento dentário se encontra na posição horizontal (figura: 4) quando, a coroa do terceiro molar estiver em íntimo contato com a raíz distal do segundo molar, em uma inclinação ao redor de 90 graus. Esta impactação é também considerada rara, ocorrendo em apenas $3 \%$ da população e, possui alta complexidade de remoção. $(2,4,5,6)$

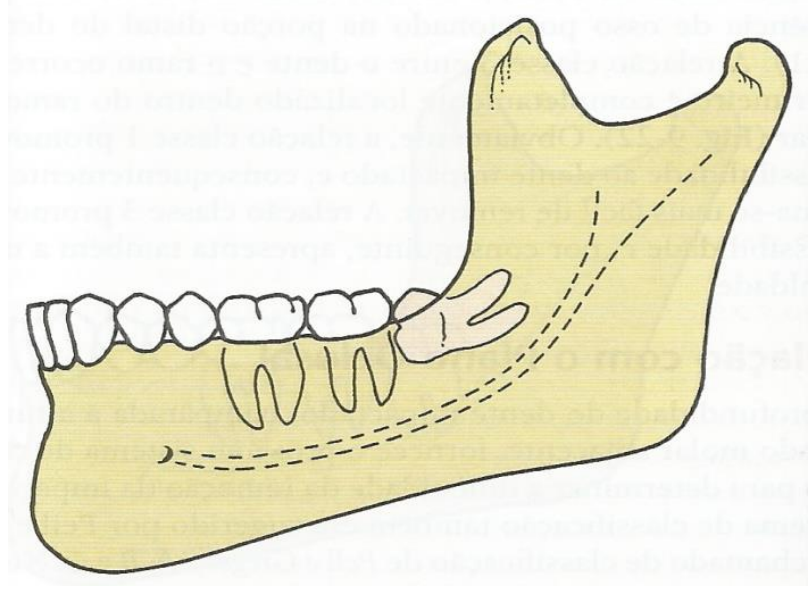

Fig. 4: Apresenta angulação horizontal.

Em raros casos, o terceiro molar impactado pode se encontrar em posição transversal, ou seja, a coroa pode estar posicionada em direção lingual, sendo assim, denominada como linguoangular; ou então, a coroa pode estar inclinada em direção vestibular, sendo denominada vestíbuloangular. ${ }^{(2,5,6)}$

Vasconcelos e colaboradores (2002), observando 450 radiografias panorâmicas, avaliaram a prevalência de terceiros molares impactados em relação a Rev. Psicol Saúde e Debate. Jan., 2017:3(1):34-49. 
classificação de Winter. Dados concluíram que as posições mais frequentemente encontradas foram a mesioangulada e a vertical. (4)

Outras duas classificações também são bastante difundidas entre profissionais e, que também possuem grande importância, são a classificação quanto ao ramo da mandíbula (válida apenas para molares inferiores) e a classificação de relação com o plano oclusal. Ambas foram desenvolvidas por Pell \& Gregory e, em relação ao ramo da mandíbula, são as seguintes:

Classe 1 - se houver espaço suficiente para irrupção do terceiro molar, ou seja, entre a borda anterior do ramo da mandíbula e a distal do segundo molar (figura: 5). ${ }^{(4,5,6)}$

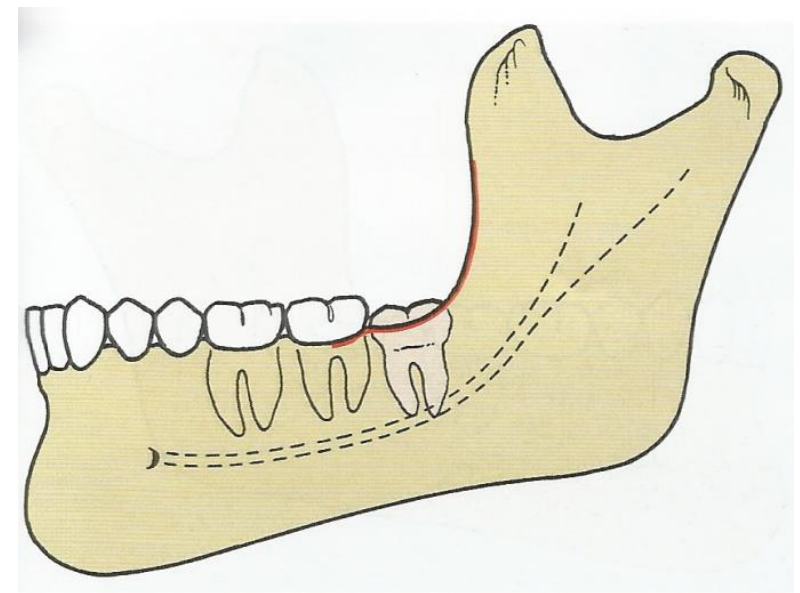

Fig. 5: Impactação classe 1.

Classe 2 - se houver espaço mésio-distal entre o ramo da mandíbula e a distal do segundo molar, mas o mesmo não possibilita comprimento suficiente para o irrompimento do terceiro molar (figura: 6 ). ${ }^{(4,5,6)}$

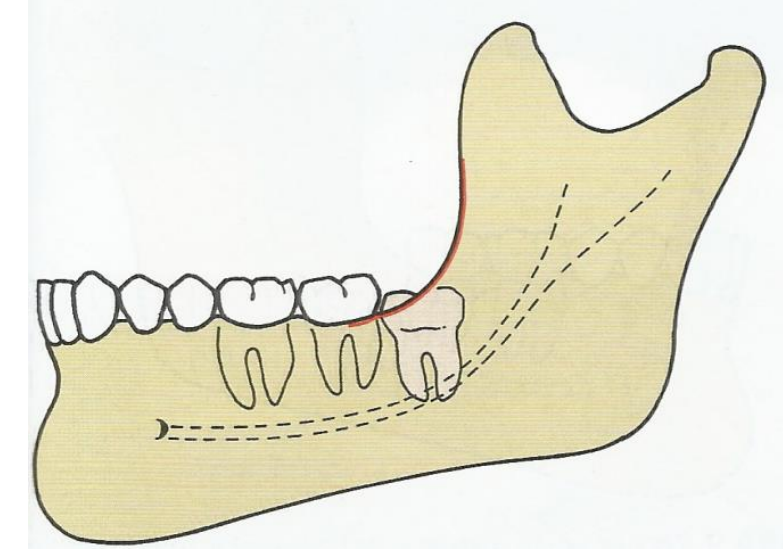

Fig. 6: Impactação classe 2.

Rev. Psicol Saúde e Debate. Jan., 2017:3(1):34-49. 
Classe 3 - ocorre quando o terceiro molar estiver completamente impactado pelo ramo anterior da mandíbula (figura: 7$)$. $(4,5,6)$

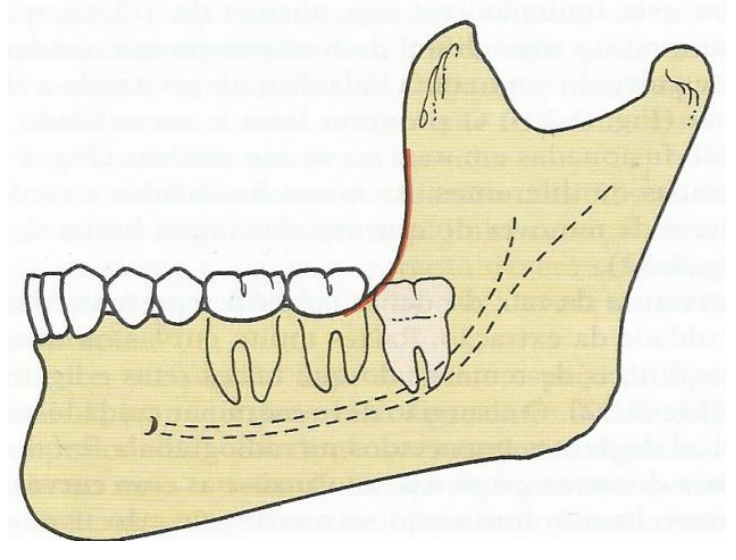

Fig. 7: Impactação classe 3

Em relação com o plano oclusal, a dificuldade da remoção do elemento dentário é medida pelo nível de impactação (profundidade) do dente, ou seja, o nível de dificuldade é diretamente proporcional ao nível de impactação.

Classe A - quando a face mais alta do terceiro molar estiver ou no mesmo plano do segundo molar, ou, acima (figura: 8). ${ }^{(4,5,6)}$

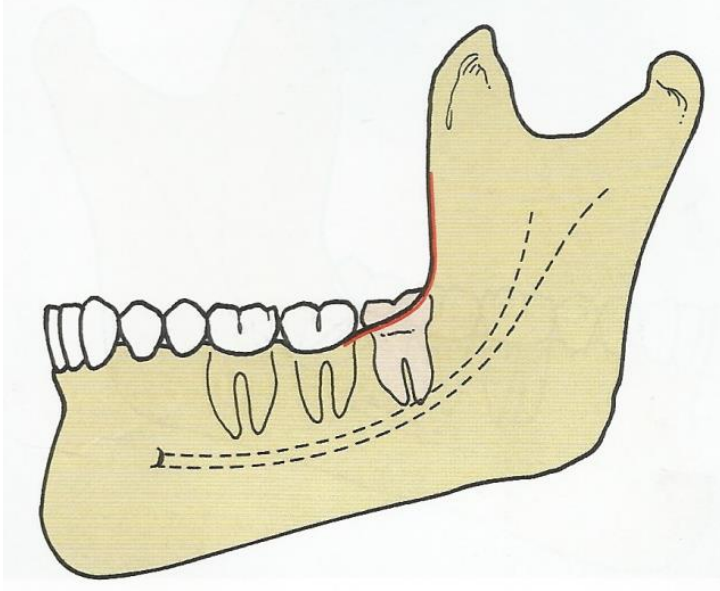

Fig. 8: Impactação classe A.

Classe B - quando a face mais alta do terceiro molar estiver localizada entre o plano oclusal e a linha cervical do segundo molar (figura: 9). ${ }^{(4,5,6)}$ 


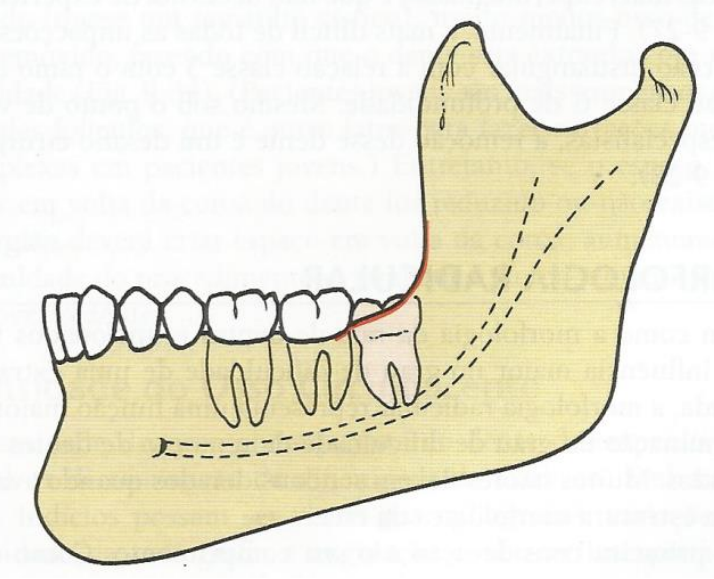

Fig. 9: Impactação classe B.

Classe $\mathrm{C}$ - quando a face mais alta do terceiro molar estiver localizada abaixo da linha cervical do segundo molar (figura: 10). ${ }^{(4,5,6)}$

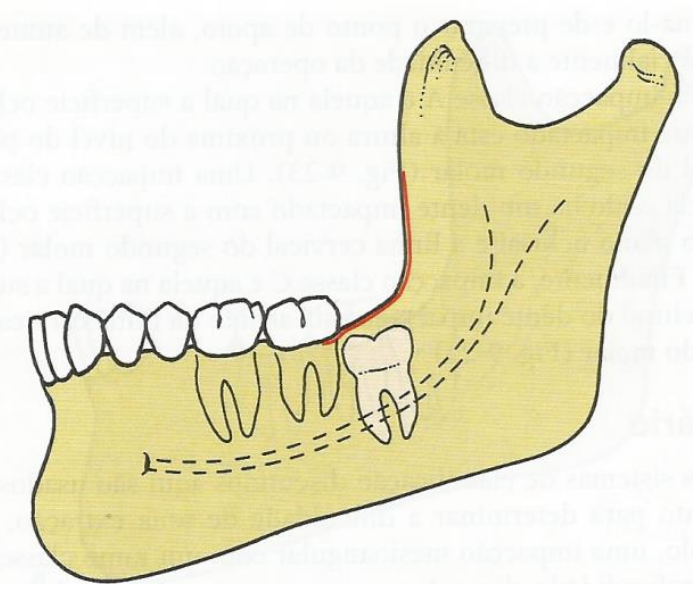

Fig. 10: Impactação classe C.

Farias e colaboradores (2003), observaram a impactação classe II, que se mostrou em maior número (72,8\%), e as classes A e B demostraram valores entre $(47,6 \%$ e $43,7 \%)$. (4)

\section{Indicações e contraindicações para extração de terceiros molares}

A remoção de terceiros molares superiores e inferiores inclusos é bastante difundida e comum entre profissionais bucomaxilofaciais. ${ }^{(10,16)}$

Dento das limitações existentes na exodontia de terceiros molares, existem as disfunções temporomandibulares (DTM), caracterizadas como: conjunto de problemas musculares e articulares associados à mastigação, má funcionamento da 
mandíbula, crepitação, luxação e dor, assim como a limitação do grau de abertura mandibular, dificultando a cirurgia de extração dos terceiros molares. ${ }^{(17)}$

Ademais, há uma enorme controversa entre pesquisadores, na real necessidade de extração destes elementos e na indicação e contraindicação. Alguns autores contraindicam a remoção profilática (cirurgia que visa a prevenção de futuras complicações inerentes a presença de terceiros molares inclusos na cavidade oral) de terceiros molares, pelo fato do desconhecimento científico pelo momento ideal da irrupção do mesmo e por relatarem a importância da permanência deste elemento como possível substituto em função do primeiro e segundo molares anteriormente extraídos. Outros, reforçam que complicações cirúrgicas provenientes da extração não são incomuns, como: parestesia, hemorragias, trismo, deiscências, osteíte alveolar e fratura mandibular. ${ }^{(10,16,17)}$

Outro argumento bastante relevante para se manter terceiros molares na cavidade oral é a possível obtenção de células-tronco a partir de elementos dentários sadios, que possibilita novas perspectivas à medicina regenerativa. ${ }^{(16)}$

Em pacientes com idade avançada, a extração torna-se limitada, pelo fato de estes apresentarem a cortical óssea mais calcificada, o que dificulta a luxação do dente e se faz necessário maior quantidade de remoção óssea para que a exérese seja efetuada. Pacientes idosos também passarão por um pós-operatório mais complicado, com desconforto que pode chegar entre 4 a 5 dias e complicações pósoperatórias com aumento significativo nesta faixa etária. ${ }^{(6,16)}$

No entanto, dentre os autores que indicam a remoção profilática de terceiros molares, estes relatam uma série de consequências sérias da permanência destes elementos na cavidade oral, dando maior ênfase em lesões patológicas que podem predispor ao desenvolvimento de alterações malignas, como os tumores odontogênicos. ${ }^{(16)}$

O ameloblastoma é o tumor odontogênico mais comum de ocorrer nesta região e deve ser removido. A permanência do terceiro molar impactado também pode predispor o desenvolvimento de cistos, como o ceratocisto e o cisto dentígero. (6)

Rev. Psicol Saúde e Debate. Jan., 2017:3(1):34-49. 
O momento ideal para a remoção de terceiros molares impactados, se estes forem indicados, abrange uma idade entre 17 e 20 anos. Pacientes mais jovens se adequam melhor ao procedimento cirúrgico, tanto durante a cirurgia (raíz incompleta, com 1/3 formada e cortical óssea menos densa, que facilitam 0 procedimento operatório) quanto no pós-operatório (melhor recuperação e menor influência no cotidiano do paciente). (6)

Dentre as indicações para remoção de terceiros molares impactados, podemos citar: prevenção de cáries dentárias (neste caso, o início da cárie dentária se dá pelo acúmulo de bactérias entre a região distal do segundo molar e a mesial do terceiro molar), prevenção da doença periodontal (pelo fato do déficit de osso alveolar na distal do segundo molar, o que influencia diretamente na dificuldade de higienização e deslocamento apical da junção gengival), prevenção de pericoronarite (terceiros molares semi-impactados podem apresentar um tecido gengival que cobre parcialmente a coroa, denominado opérculo, onde acumula alimento e causa inflamação e dor), prevenção de reabsorção radicular (em alguns casos pela pressão exercida de um dente impactado sobre a raíz de outro), dor sem origem aparente, razões ortodônticas e dentes não-funcionais . ${ }^{(6,16)}$

\section{CONSIDERAÇÕES FINAIS}

Há, atualmente, na literatura, uma grande controversa em relação a extrair ou não terceiros molares impactados. Alguns autores defendem a extração profilática destes elementos para prevenir futuras complicações como: cáries dentárias, lesões periodontias, pericoronarites, tumores odontogênicos, etc. Outros visam a idade dos pacientes como fator predominante para indicação das cirurgias.

$E$, ainda, há aqueles que defendem a permanências desses elementos dentários pelo desconhecimento do momento de erupção na cavidade bucal e a ocorrência de complicações pós-operatórias. O que é importante focar, em cada caso clínico, é o custo-benefício de cada cirurgia e, o uso pelo profissional dentista, de todo o artefato que o mesmo dispõe para realizar o melhor diagnóstico e plano de tratamento para cada caso.

\section{REFERÊNCIAS}

Rev. Psicol Saúde e Debate. Jan., 2017:3(1):34-49. 
1. Ribeiro ED, Lima-Júnior JL, Barbosa JL, Haagsma IB, Lucena LNS, Marzola C. Avaliação das posições de terceiros molares retidos em relação à classificação de Winter. Revista de Odontologia da UNESP. 2008; 37(3): 203-209.

2. Vannucci MG, Fritzen TN, Moraes JFD, Weber JBB, Hellwig I, Oliveira MG, et al. Estudo comparativo da variabilidade da posição dos terceiros molares retidos em pacientes adolescentes e adultos jovens. Canoas: Stomatos. 2010; 16(31): 4-13.

3. Costa MA, Oliveira AE, Costa JF, Silva RA, Lopes FF, Silva APB. Incidência das posições anatômicas e agenesia dos terceiros molares em estudantes de São Luiz, Maranhão. João Pessoa: Pesq Bras Odontoped Clin Integr. 2010; 10(3): 399-403.

4. Nery FS, Santos LD, Sarmento VA, Santana EJ. Avaliação da prevalência de terceiros molares inferiores inclusos e da posição e inclinação do seu longo eixo em radiografias panorâmicas. Salvador: R. Ci. méd. Biol. 2006; 5(3):222-230.

5. Júnior PV, Marson JO, Toyama RV, Santos JR. Terceiros molares inclusos mandibulares: incidência de suas inclinações segundo classificação de winter: levantamento radiográfico de 700 casos. Porto Alegre: RGO. 2007; 55(2): 27-31.

6. Peterson LJ. Cirurgia oral e maxilofacial: contemporânea. 5. ed Rio de Janeiro: Elsevier; 2005. p. 153-192.

7. Xavier CR, Ribeiro ED, Rocha JF, Duarte BG, Júnior OF, Ana ES, et al. Avaliação das classificações dos terceiros molares impactados de acordo com as classificações de Winter e Pell \& Gregory em radiografias panorâmicas. Camaragibe: Rev. Cir. Traumatol. BucoMaxilo-fac. 2010; 10(2): 83-90.

8. Santos DR, Quesada GA. Prevalência de terceiros molares e suas respectivas posições segundo as classificações de Winter e de Pell e Gregory. Camaragibe: Rev. Cir. Traumatol. Buco-Maxilo-fac. 2009; 9(1): 83-92.

9. R Elias. Terceiros molares: Quando submetê-los a cirurgia. Rev. Cispre.2008.

10. Gomes AC, Silva ED, Bezerra TP, Pontual MM, Vasconcelos ZR. Terceiros molares: o que fazer?. Revista de Cirurgia e Traumatogia Buco-Maxilo-Facial. 2004; 4(3): 137-143.

11. Gartner CF, Goldenberg FC. A importância da radiografia panorâmica no diagnóstico e no plano de tratamento ortodôntico na fase de dentadura mista. São Bernardo do Campo: Revista Odonto. 2009; 17(33): 102-109.

12. Silva DN, Bezerra MF, Guimarães KB, Brucker MR. Métodos radiográficos no diagnóstico de quartos molares mandibulares. RFO. 2007; 12, (2): 79-83. 
13. Primo BT, Andrade MG, Oliveira HW, Oliveira MG. Dentes restidos: novas perspectivas de localização. Passo Fundo: RFO. 2011; 16(1): 95-99.

14. Lima IL, Silva AIV, Oliveira F J, Cardoso FO, Manzi FR. Radiografias convencionas e tomografia computadarizada cone-beam para localização de dentes inclusos: relato de caso. Arq bras odontol. 2009; 52: 58-64.

15. Trento,Luciano C, Zini, Moreira M, Moreschi, Eduardo, Zamponi, Manfredo, Gottardo, Paulo J. Localização e classificação de terceiros molares: análise radiográfica. Interbio. 2009; 3(2): 18-23.

16. Normando D. Terceiros molares: extrair ou não extrair?. Dental Press J Orthod. 2015; 20(4): 17-8.

17. Braga Ac, Souza FLD. Transtornos Psicológicos Associados à Disfunção Temporomandibular. Revista Psicologia e Saúde em Debate. 2016; 2(1): p. 100-120.

Rev. Psicol Saúde e Debate. Jan., 2017:3(1):34-49. 